\title{
¿VOLVER A LA CONSTITUCIÓN DE 1925? UNA PROPUESTA SIN FUNDAMENTO HISTÓRICO
}

\author{
A RETURN TO THE CONSTITUTION OF 1925? \\ A PROPOSAL WITHOUT A HISTORICAL BASIS
}

\begin{abstract}
ENRIQUE BraHM GARCÍA*
RESUMEN: Frente a quienes han planteado la alternativa de "volver" a la Constitución de 1925 y así a la "tradición constitucional chilena", para usarla como base para dar forma a una nueva institucionalidad, en este trabajo se plantea que no es clara la continuidad entre las constituciones de 1828 y 1833 y tampoco la que une a esta con la de 1925. Además, en ambos casos se puede discutir su legitimidad de origen y en lo que se refiere a esta última, también la afirmación de que se habría legitimado en su ejercicio.
\end{abstract}

Palabras clave: Constitución, legitimidad, origen, ejercicio, caudillismo militar.

ABSTRACT: Regarding those who have favored the alternative of "returning" to the Constitution of 1925 - hence, back to the "Chilean constitutional tradition" - as the foundation in shaping a new institutional order, this paper states that there is no clear continuity between the 1828,1833 and 1925 constitutions. Furthermore, the legitimacy by origin in both former cases is debatable, as well as latter's legitimization by exercise.

Keywords: Constitution, legitimacy, origin, exercise, military caudillismo.

\section{INTRODUCCIÓN}

Hace unos años, durante el último gobierno de Michelle Bachelet, se empezó a imponer en ciertos círculos la necesidad que habría de elaborar un nuevo texto constitucional. La Constitución Política de 1980 -la "de Pinochet", aunque desde las profundas reformas de 2005 lleva la firma del presidente Ricardo Lagos-, pese a que de sus 120 artículos originales, apenas unos veinte no han sufrido modificaciones ${ }^{1}$, debía ser reemplazada por otra más adecuada a los nuevos tiempos... y que no estuviera asociada a la figura del "dictador". Se abrió así una verdadera caja de Pandora, pues, con espíritu refundacional y revolucionario, sectores de la izquierda postularían la premisa de que lo que correspondía era partir de cero para dar forma, a través de una asamblea constituyente o de otras fórmulas, que no se ceñirían a las normas sobre reforma contenidas en la constitución vigente, a un texto constitucional completamente nuevo.

\footnotetext{
Doctor en Derecho por la Universidad de Frankfurt/M. Profesor de la Facultad de Derecho y del Instituto de Historia de la Universidad de los Andes (Chile), Dirección Postal: Universidad de los Andes, Facultad de Derecho, Av. Mons. Álvaro del Portillo 12455, Las Condes, Santiago de Chile. Dirección electrónica: ebrahm@uandes.cl.
}

1 Alvarado (2016) p. 35. 
En ese contexto se levantaron voces que, si bien se mostraban de acuerdo con la necesidad que habría de sustituir la Constitución de 1980, tenían temor ante los resultados a los que se podría llegar al redactar ex nihilo una nueva carta política. De ahí que propusieran tomar como base para la reforma, para la discusión de la que debería surgir un nuevo texto constitucional, la Constitución Política de $1925^{2}$.

Los principales exponentes de esta posición acaban de publicar un libro en el cual fundamentan su propuesta ${ }^{3}$. Según se señala en la introducción del mismo, aunque los autores enfrentan la cuestión desde perspectivas distintas -el Derecho, la Historia, la Sociología, la Filosofía y las Ciencias políticas- coincidirían en tres puntos fundamentales. En primer lugar, están convencidos de que "en Chile existía una 'tradición constitucional' que fue radical y revolucionariamente interrumpida en 1973”. Ello porque la Constitución de 1980, a diferencia de sus antecesoras, habría sido concebida "como una nueva constitución, marcando así una diferencia sustancial con las de 1833 y 1925, que fueron pensadas siempre como "reformas" de sus predecesoras" ${ }^{4}$. En segundo lugar, pese a reconocer que la generación de la Constitución de 1925 no fue plenamente democrática -aunque habría sido solo una reforma de la de 1833-, se legitimó en su ejercicio. Tan es así que incluso en agosto de 1973, en medio de la crisis terminal del régimen de gobierno que ella había inaugurado, "tanto la derecha como la izquierda utilizaron la Constitución de 1925 -y el régimen presidencial por ella garantizado- para justificar sus respectivos proyectos, los primeros acusando de 'inconstitucionalidad' al Gobierno de Allende, los segundos amparándose en la Constitución con el fin de evitar un alzamiento militar" ${ }^{5}$. Por último, considerando que la historia constitucional chilena habría sido "reformista y gradual", y para evitar "tanto el inmovilismo de alguna derecha como el radicalismo de cierta izquierda", se postula que la discusión constitucional debería "anclarse en la de 1925", sin perjuicio de las reformas que se le debería introducir.

Por lo demás, con matices y diferencias, también han adherido a la postura de recurrir a la Constitución de 1925 para terminar con la de 1980 otros autores. Es el caso, por ejemplo, de Claudio Alvarado ${ }^{6}$, Carlos Peña ${ }^{7}$, y, en un sentido distinto, Fernando Atria ${ }^{8}$.

¿Tendrá algún sentido volver a 1925? En lo inmediato, a primera vista, y sin ahondar todavía en argumentos histórico-jurídicos, no parece esta una solución muy sensata. Por ejemplo, en una perspectiva comparada, en su momento, desde el año de su promulgación -1919- y en la década de los veinte, la Constitución de Weimar gozó de un inmenso

\footnotetext{
2 Confróntese con los textos - cartas y columnas publicadas en diversos medios- recopilados en el anexo de FONTAINE et al. (2018) pp. 237 ss.

3 Fontaine et al. (2018).

4 Fontaine et al. (2018) p. 18.

5 Fontaine et al. (2018) pp. 18 ss.

6 Alvarado (2016) El Mercurio (12/3/2016) p. A 2.

7 El Mercurio (2/3/2016) p. A 2.

8 Atria (2013). Allí se propone en la página 76 "un proceso de dictación de una nueva Constitución en el que decidamos por referencia a la última decisión constitucional que fue aceptada en su momento por todos y que no contenía trampas, es decir, la Constitución de 1925 en su estado posterior a la última reforma en democracia, en 1971. Imaginemos que esa Constitución es la que cuenta como nuestra 'hoja en blanco', es decir como la decisión que vale cuando no alcancemos acuerdo para decidir".
} 
prestigio (de hecho, fue uno de los modelos considerados por nuestros constituyentes de $1925)^{9}$. Pero ese prestigio se perdió desde el momento en que sus mecanismos permitieron la llegada de Adolfo Hitler al poder en $1933^{10}$. De ahí que se tuviera buen cuidado en no tomarla como modelo cuando se redactó la Grundgesetz de $1949^{11}$. Guardando las proporciones, tampoco la Constitución de 1925 fue un texto fundamental exitoso. Bajo su vigencia el régimen político se fue trabando y radicalizando cada vez más y se dio un crecimiento económico bajísimo, todo lo cual confluyó en provocar la crisis terminal del sistema en $1973^{12}$. ¿Qué justifica volver a ella si sus resultados prácticos fueron tan negativos?

Por contraste, la Constitución que se quiere eliminar de raíz ha demostrado ser exitosa. Como reconoce el mismo Arturo Fontaine, "se trata de una Constitución que encauzó con éxito una transición pacífica a la democracia”. Luego agregaba: "además, ha sido la Constitución de años en los que Chile ha conseguido logros admirables; entre ellos, dejar de ser un país de pobres y pasar a ser un país donde predominan las clases medias. Y, sin duda, algunas de sus instituciones han jugado un papel decisivo en ello"13. Vale la pena recordar también que, a nivel mundial, "cerca del $20 \%$ de las constituciones vigentes actualmente fueron redactadas durante períodos no democráticos" 14 .

Sería quedarse en el mero formalismo jurídico el fundar la continuidad constitucional chilena en el hecho de que las constituciones de 1833 y de 1925 se presentaron como "reformas" a las anteriores, mientras los constituyentes de 1980 hablaron siempre de reemplazar la de 1925 por una nueva. En efecto, más allá de las palabras, la Constitución de 1980 no partió de la nada, sino que mantuvo buena parte del entramado esencial -régimen presidencial, bicameralismo, etc.- de la Constitución anterior, pero pretendió corregir aquellos aspectos de la misma que más habrían contribuido a su fracaso. Así, por poner algunos ejemplos, en lo electoral, el sistema binominal reemplazó al proporcional que tanto había contribuido a fraccionar el sistema político y a rigidizarlo en los clásicos tres tercios y se incluyó la segunda vuelta para asegurar que los presidentes gobernaran con mayoría; el Banco Central debía evitar los abusos que se habían cometido en el ámbito económico; con el recurso de protección los privados tendrían un medio de defensa original; en materia de derecho de propiedad, después de los extremos a los que se había llegado en los últimos años de vigencia de la Constitución de 1925, se volvería a los términos clásicos del constitucionalismo liberal del siglo XIX.

Más allá de lo anterior, parece una construcción algo simplista y voluntarista la que postula la existencia de una "tradición constitucional" en la que se sustenta buena parte de la argumentación de quienes defienden la vuelta a 1925. En efecto, no es clara la continuidad entre las constituciones de 1828 y 1833, y tampoco la que une a esta con la de 1925.

\footnotetext{
9 Brahm (2012) pp. 239 ss. y Actas (1926) pp. 86 ss.

10 BRAHM (2013) pp. 45 ss.

11 Hildebrandt (1979).

12 Confróntese con la ponencia de Gonzalo Vial y el comentario de René Millar en TAgLe (1992) pp. 267 ss.

13 Fontaine et al. (2018) pp. 23 ss. Confróntese con la Carta de Francisco Prat, El Mercurio (9/3/2016) p. A 2.

14 Ginsburg (2014) p. 1.
} 
Además, en ambos casos se puede discutir su legitimidad de origen y, en lo que se refiere a esta última, también el que se hubiere legitimado en su ejercicio.

De acuerdo con lo anterior, el trabajo se estructurará en tres capítulos. Uno referido a los aspectos esenciales relacionados con la redacción de la Constitución de 1833. En el siguiente se pretende demostrar la ilegitimidad de origen de la Constitución de 1925. El último se refiere a los cuestionamientos que se le hicieron a esta, desde todos los sectores políticos, hasta el quiebre institucional de 1973.

\section{DE 1828 A 1833}

Como es bien sabido, la Constitución Política de 1828, promulgada durante el gobierno de Francisco Antonio Pinto, tuvo una efímera vigencia. En efecto, los abusos que se dieron en materia eleccionaria al poner en ejecución la misma y que culminaron con la arbitrariedad en que incurrió el Congreso recién elegido de mayoría "pipiola" para proclamar como Vicepresidente de la República al liberal Joaquín Vicuña en desmedro de las dos primeras mayorías detentadas por el pelucón Francisco Ruiz-Tagle y el o'higginista Joaquín Prieto, sirvieron de catalizador para el estallido de una revolución que pondría fin al período de ensayos constitucionales o de anarquía. Según señalaba Jaime Eyzaguirre, "el audaz paso iba a colmar la paciencia de los opositores y a precipitarlos resueltos a la liquidación del régimen. 'Pelucones' y 'Estanqueros', unidos en un solo haz, se aprestaron a actuar sin demora y con ellos los pocos y resueltos o'higginistas. El hábil juego dialéctico de su jefe José Antonio Rodríguez Aldea, unido a la firmeza en el obrar de Portales y Gandarillas, imprimían claro rumbo a la revolución"15.

Terminada la guerra civil con el triunfo conservador, estos no estuvieron dispuestos a ceñirse a lo dispuesto por la constitución vigente -se consideraba que el régimen de gobierno en ella establecido no era el más adecuado para las realidades de Chile- en orden a que ella solo podía reformarse a partir del año 1836. Contra lo dispuesto en la carta de 1828 , tras una serie de artículos que abogaban por el adelanto de los plazos constitucionales publicados por Manuel José Gandarillas en El Araucano y de un oficio al efecto dirigido por el Cabildo de Santiago al Vicepresidente de la República que este hizo llegar al Congreso de Plenipotenciarios, se acordó con el Ejecutivo encargar al Congreso Nacional que se ocupara de su pronta reforma ${ }^{16}$. De esta forma, el 13 de julio de 1831 el Senado elaboraba un proyecto de ley en el que, tras atribuir a la Constitución de 1828 "la horrible crisis en que acaba de verse envuelta la Nación, sumergida en todos los horrores de la guerra civil, la anarquía y el desorden, de que solo ha podido salvarse por un especial favor de la Divina

\footnotetext{
15 Eyzaguirre (1977) p. 471. Una visión distinta en relación con la génesis de la Constitución de 1828 y su inmediato fracaso, se puede encontrar en Salazar y Pinto (1999) p. 31; Pinto y Valdivia (2009) p. 169; y SALAZAR (2005) pp. 4, 27 y 443.

16 Las principales fuentes para estudiar este período de nuestra historia constitucional se encuentran en las Sesiones de los Cuerpos Legislativos (1887), tomo XIX ss. Confróntese con Galdames (1925) pp. 863 ss. y Carrasco (1983) pp. 53 ss.
} 
Providencia”, determinaba que se convocara de inmediato a una Gran Convención para reformarla ${ }^{17}$.

En el seno de la misma se enfrentarían muy pronto las posiciones de Mariano Egaña y la de Manuel José Gandarillas. Mientras el objetivo de este último era llevar adelante una reforma de la Constitución de 1828 que, respetando su contenido esencial y su espíritu, corrigiera tan solo algunas de sus normas, Egaña pretendía cambiar de forma radical el régimen de gobierno, aunque manteniendo el sistema republicano representativo ${ }^{18}$. Estas diferencias se mantendrían durante la discusión de la reforma dentro de la Comisión nombrada al efecto. De esta forma, cuando en abril de 1832 los comisionados dieron por concluido su trabajo, Egaña manifestaría su desacuerdo con el mismo presentando luego un proyecto propio que pasaría a ser conocido como el "Voto particular" de Egaña ${ }^{19}$. Este se alejaba en aspectos fundamentales de las normas de la constitución vigente, como queda en evidencia con solo revisar alguna de las duras críticas que recibió, apenas se filtrara su contenido a la prensa. Por ejemplo, según el periódico El Hurón, dicho proyecto "solo podía convenir a los turcos o a los chinos". Luego sostenía -tras hacer una síntesis de las atribuciones que se concedían al Ejecutivo- que de promulgarse ese texto "no tendríamos jamás otras leyes que las que quiera darnos el Gobierno, y si el Presidente de la República no se convierte en un monarca absoluto, será solamente porque no quiere" ${ }^{20}$.

Aunque algunas de las propuestas más extremas consideradas en el "Voto particular" no tuvieron cabida en el texto definitivo de la Constitución Política de 1833, es evidente que los convencionales terminaron por recoger lo fundamental de su contenido ${ }^{21}$. De ahí que, más allá del formalismo de que se la considerara como una mera reforma a la 1828, en realidad se trataba de una obra nueva. Si bien Mariano Egaña había tomado elementos de la tradición constitucional nacional -que no se limitaban a la del 28, sino que también incluía la de O'Higgins de 1822 y la de su padre, don Juan, de 1823- también integró instituciones nuevas, como el "estado de sitio", y armó una estructura que debía mucho a los modelos napoleónicos y a los de la restauración francesa que le daban un cariz radicalmente diferente al texto vigente, dotando de amplísimas facultades al titular del poder ejecutivo ${ }^{22}$. No en vano entre ambas constituciones habían mediado una revolución y una guerra civil que se definió en Lircay con la derrota de las fuerzas defensoras del régimen liberal.

Por lo demás, se era consciente de que con ella se ponía fin a una época que había comenzado con las guerras de la independencia, y que se iniciaba una nueva. Como lo expresaba el Presidente Joaquín Prieto al presentar el nuevo texto constitucional, los convencionales "despreciando teorías tan alucinadoras como impracticables, solo han fijado su atención en los medios de asegurar para siempre el orden y la tranquilidad pública contra los riesgos de los vaivenes de partidos a que han estado expuestos. La reforma no es más

17 Sesiones de los Cuerpos Legislativos (1887), tomo XiX, p. 130, sesión de 13 de julio de 1831.

18 Sesiones de los Cuerpos Legislativos (1887), tomo XXI, p. 14 y Barros Arana (1902), tomo XVI, p. 307.

19 Sesiones de los Cuerpos Legislativos (1887), tomo XXI, pp. 47 ss. y 84 ss.

20 Sesiones de los Cuerpos Legislativos (1887), tomo XXI, p. 26; y El Hurón (22/5/1832).

21 Welsch (1977).

22 Brahm (2007) pp. 100 ss. 
que el modo de poner fin a las revoluciones y disturbios, a que daba origen el desarreglo del sistema político en que nos colocó el triunfo de la independencia" ${ }^{23}$.

Por todo lo anterior no nos parece que pueda decirse que "la Constitución de 1833 haya sido pensada y desarrollada desde, no en contra de la Constitución de 1828”, como hace Juan Luis Ossa ${ }^{24}$, sin perjuicio de que resulta evidente que -pese a su autoritarismoella se mantenía dentro de los cauces liberales dominantes, por lo que "contenía las semillas de su propia liberalización” ${ }^{25}$. Los conservadores chilenos también formaban parte del gran tronco liberal ${ }^{26}$.

\section{LA GÉNESIS ESPURIA DE LA CONSTITUCIÓN DE 1925}

Quienes postulan la conveniencia de volver a la Constitución de 1925 tienden a minimizar sus problemas de legitimidad de origen. "Aunque su método de producción fue imperfecto, señala Hugo Herrera, la de 1925 es una Constitución concebida en democracia"27. En opinión de Arturo Fontaine, Arturo Alessandri "traspasó su carisma democrático a la Constitución"28. Para Juan Luis Ossa, por su parte, la Constitución de 1925 no rompió con la "tradición constitucional chilena" y habría contado con el apoyo de las distintas fuerzas políticas ${ }^{29}$.

La verdad es muy distinta. La Constitución de 1925 fue impuesta por los militares y Alessandri, contra la opinión de la mayoría de la clase política, por medios no contemplados en el texto constitucional vigente, en un ambiente revolucionario y de excepcionalidad constitucional, luego de un plebiscito en el que participó menos de la mitad del cuerpo electoral, celebrado en condiciones poco democráticas, pues ni siquiera había plena libertad de prensa $^{30}$.

Debe recordarse que con la intervención militar de septiembre de 1924 -el "ruido de sables" - se inició un proceso revolucionario y un período de inestabilidad política que se extendió hasta fines de 1932. En ese contexto, el 11 de septiembre de 1924, los militares jóvenes, constituidos en una Junta Militar, de la que ya había pasado a ser una de sus figuras clave Carlos Ibáñez del Campo, daba a conocer un "Manifiesto" con sus postulados. Allí se señalaba: "Nuestra finalidad es convocar a una libre Asamblea Constituyente, de la cual surja una Carta Fundamental que corresponda a las aspiraciones nacionales"31. Estaba claro que el movimiento militar que dominaría la política chilena durante los próximos años no se contentaba con reformar la Constitución vigente, sino que buscaba transfor-

\footnotetext{
23 Valencia (1986) p. 172.

24 Fontaine (2018) p. 70.

25 Jaksic y Serrano (2010) p. 75.

6 Confróntese con Brahm García (1992) y (2007), y Collier (2005) p. 172.

Fontaine et al. (2018) p. 189.

8 Fontaine et al. (2018) p. 39.

FontAine et al. (2018) p. 76.

${ }^{0}$ Confróntese con, por ejemplo, Correa (2015) pp. 58 ss.

Escobar e Ivulic (1984) p. 138.
} 
marla de raíz. No en vano se habían propuesto "abolir la política gangrenada" 32 que estaba destruyendo Chile.

Al mismo tiempo asumía el gobierno del país una Junta Militar, integrada por los generales Altamirano y Bennet y por el almirante Nef, y se disolvía el Congreso Nacional. El Presidente de la República Arturo Alessandri que había pretendido instrumentalizar en su favor el movimiento militar, había presentado su renuncia después de que, tras aprobarse el 8 de septiembre un paquete de leyes sociales exigidas por los militares, estos no volvieron a sus cuarteles como él esperaba. En efecto, Ibáñez y el grupo que lo apoyaba habían hecho publicar un acuerdo en el que se señalaba: "El movimiento militar está inspirado exclusivamente en la necesidad suprema de salvar a la Nación arruinada por la corrupción política y administrativa, y no terminará mientras no realice ampliamente su misión”33. Estaba claro en manos de quién estaba el poder y de que se buscaba cambiar de raíz el régimen de gobierno. En todo caso el Senado no aceptó la renuncia de Alessandri y solo le otorgó una licencia de seis meses y permiso para abandonar el territorio nacional ${ }^{34}$.

Chile había entrado en una etapa de excepcionalidad constitucional, lo que se confirmó cuando en el mes de enero de 1925 la Junta de Gobierno fue derribada por un golpe de estado encabezado por Carlos Ibáñez del Campo y Marmaduke Grove. El movimiento de la oficialidad joven no estaba de acuerdo con el rumbo que había impuesto al gobierno la Junta que encabezaba el General Altamirano. De inmediato llamarían a Alessandri para que volviera a terminar su período constitucional ${ }^{35}$.

No deja de ser paradójico que quienes habían precipitado la renuncia del Presidente de la República, ahora lo llamaran de vuelta. Pero la verdad es que, más allá de sus diferencias, Alessandri y los militares jóvenes coincidían en la necesidad que había de terminar con el régimen parlamentario y reemplazarlo por uno de tipo presidencial. Además, se necesitaban mutuamente: los militares tenían el poder; Alessandri, en cambio, los conocimientos jurídicos y la habilidad política que se requerían para introducir cambios profundos en la institucionalidad.

Pero sea lo que fuere lo que pretendiera o esperara Alessandri, era un hecho que de vuelta en Chile en el mes de marzo de 1925 y de lo apoteósica que fue su recepción, su poder ya no tenía un sustento democrático, sino que se asentaba en el apoyo militar. Incluso su "carisma” se vería menoscabado. Si bien consiguió que se promulgara una nueva Constitución, no lograría terminar su mandato; tampoco dejar un sucesor de su preferencia en 1925, y sería derrotado por Juan Esteban Montero, el candidato de los partidos tradicionales, en las presidenciales que siguieron a la caída de Ibánez ${ }^{36}$. Poco antes de su llegada, Carlos Ibáñez le había señalado con claridad por medio de una carta lo que se esperaba de

\footnotetext{
32 Escobar e Ivulic (1984) p. 138.

33 Cita según Vial (1986) p. 399.

34 VIAL (1986) p. 403.

35 Vial (1986) pp. 484 ss. Otra visión del choque de los caudillos, Alessandri e Ibáñez, se puede encontrar en Salazar y Pinto (1999) pp. 430 ss.

36 Collier y Sater (1998) pp. 191 ss.
} 
él: "todo ciudadano que piensa quiere ver hoy robustecido el principio de autoridad, y consagrado el de la honradez política y administrativa" 37 .

El regreso de Alessandri no se tradujo en una vuelta al gobierno civil, lo que le fue quitando el apoyo de los partidos tradicionales. Molestaba el que no hubiera cambiado el ministerio que estaba en funciones desde el golpe del 23 de enero -y que incluía como Ministro de Guerra a Carlos Ibáńez- y que hubiera nombrado como edecanes presidenciales a "prominentes oficiales del Comité Militar Revolucionario", con lo que traicionaba su promesa de que tras su llegada se volvería de inmediato "al régimen civil" y que los militares se retirarían del gobierno para cumplir con "sus funciones propias" ${ }^{38}$. En La Unión de Valparaíso se llegaba a afirmar que "el Presidente de la República está preso en las redes que le han tendido los que tramaron la conspiración del 23 de enero y designaron, como sus representantes a los actuales ministros" ${ }^{39}$. De hecho, los partidos políticos tradicionales se unirían en un "Frente Civil" 40 para enfrentar a Alessandri y a los militares. Como se señalaba con ironía en El Diario Ilustrado: "Al Presidente de la República se le concede licencia por medio de una revolución; y por medio de dos revoluciones, se pone término al permiso (...) El Ejército es esencialmente obediente, y delibera (...) La Cámara es esencialmente desobediente, pero no puede deliberar (...) La tropa asciende por actos de disciplina, y sus jefes por actos de indisciplina (...) Los Ministros juran en serio por el Manifiesto del $11 \mathrm{de}$ septiembre (...) Los partidos no creen en la existencia del gobierno civil y el gobierno militar no cree en la existencia de los partidos civiles" ${ }^{21}$.

Para los partidos resultaba inconcebible el que no se gozara de plena libertad de prensa y el que no se estuviera dispuesto a respetar la Constitución de 1833. Por ejemplo, en el mes de mayo el Senador Guillermo Bañados publicó algunos artículos en la prensa en que llamaba a que los parlamentarios volvieran a sus funciones el 1 de junio, de acuerdo a lo señalado en la Constitución. Frente a ello Alessandri habría llamado al Subdirector del Diario Ilustrado amenazándolo con la clausura si volvía a publicar artículos de ese tenor ${ }^{42}$.

En el ámbito en el que de ninguna manera se pensaba en respetar la Constitución vigente era en lo que se refería a la reforma constitucional. En su discurso de 3 de abril de 1925, ante la comisión de notables que había convocado, Alessandri señalaría que "por mucho que he pensado no encuentro otro medio para volver a la regularidad constitucional que la organización de una Constituyente que dé una nueva Constitución al país", con lo que se vulneraba el mandato constitucional que encomendaba esta tarea a las cámaras ${ }^{43}$. Ante esta afirmación presidencial, no cabía sino concluir, se constataba por El Diario Ilustrado, "que la Constitución nacional que nos regía desde 1833, ha muerto" ${ }^{44}$.

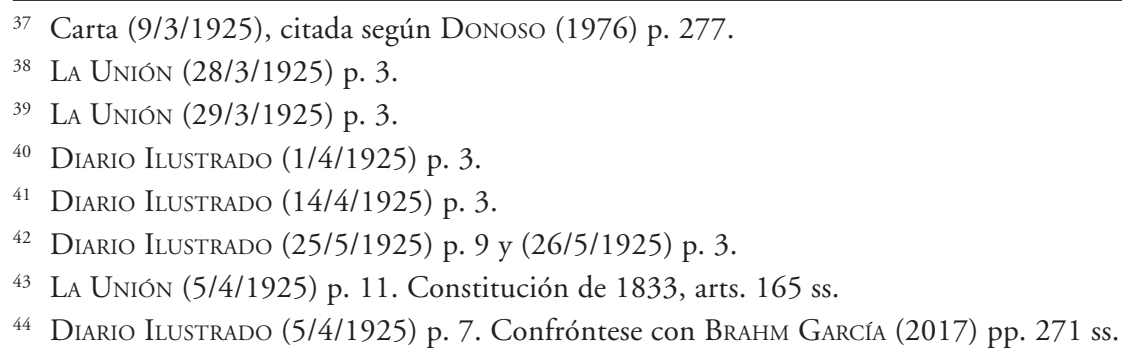


Como bien se sabe, al final no habría constituyente, sino una Comisión nombrada a dedo por el Presidente de la República en la que se incluiría a representantes de los partidos tradicionales, a independientes y a representantes del ejército y en la que el mismo Alessandri jugaría un papel central ${ }^{45}$. Por supuesto, se trataba también de un medio no contemplado en el texto constitucional vigente. Muy pronto, en el seno de la misma, se enfrentarían quienes querían introducir un régimen presidencial -Alessandri y los militares- con los representantes de los partidos que defendían el régimen parlamentario. En este predicamento estarían unidos desde los conservadores hasta los comunistas ${ }^{46}$. El empate al que se había llegado solo lo podría romper la amenazante intervención del general Navarrete en la sesión de 23 de julio. Otra vez se imponía la fuerza militar ${ }^{47}$.

Ya que no hubo asamblea constituyente, el proyecto constitucional terminó por ser plebiscitado el 30 de agosto de 1925. En medio de las circunstancias excepcionales que se vivían, la fórmula planteada por el Presidente de la República sería aprobada con el voto de 127.509 ciudadanos de un total de 302.304 inscritos $^{48}$. Se habían expresado los votantes que estaban detrás de los caudillos Alessandri e Ibáñez ${ }^{49}$.

Sin perjuicio de que formalmente la nueva Constitución se promulgó con el carácter de una reforma a la de 1833, su entrada en vigencia representó un cambio radical en el régimen de gobierno chileno. En efecto, debe recordarse que, más allá del contenido textual de la Constitución de 1833, por la vía interpretativa se había estado practicando en Chile un sistema parlamentario, desde el triunfo de las fuerzas del Congreso en la Guerra Civil de 1891. Frente al predominio del Congreso que se vivió entre 1891 y 1924, la nueva Constitución reforzaba hasta el extremo los poderes del Presidente de la República al eliminar las "leyes periódicas" (solo subsistió la de presupuestos, pero el proyecto de la misma debía ser enviado al Congreso cuatro meses antes de que empezara a regir y si no se aprobaba dentro de ese lapso regía sin más el proyecto presidencial), las prácticas parlamentarias, introducir las "urgencias" y conservar un fuerte veto presidencial: con el apoyo de un tercio más uno de los integrantes de cualquiera de las cámaras el Presidente podía bloquear el accionar del legislativo ${ }^{50}$. De ahí que para los conservadores se trataba de un régimen "sui generis, criollo", "singular e inaudito: es la autocracia presidencial con una Cámara consultiva: el absolutismo del Zar de Rusia (...) Esta concepción del poder absoluto ¡̇es militar o soviética? Parece inútil la respuesta. La democracia no puede aceptar un tiro de gracia, aunque lo

\footnotetext{
45 Vial (1986) pp. 534 ss. y Carrasco Delgado (1983) pp. 66 ss.

46 Brahm et al. (2002) pp. 16 ss. Por ejemplo, el representante comunista, Manuel Hidalgo, afirmaba: "Su partido le ha encomendado la tarea de mantener aquí (Comisión Consultiva) lo que ha sostenido en la Subcomisión, a saber, que estima preferible que el país continúe en lo que hoy se conceptúa el tan desacreditado régimen parlamentario, modificando, por supuesto, esa organización híbrida que tuvimos en la cual, en realidad, eran las camarillas las que gobernaban". ACTAS (1926) p. 426.

47 ACTAS (1926) p. 437 ss.

48 VIAL (1986) p. 548.

49 Góngora (1981) pp. 57 ss.

50 Confróntese con Brahm et al. (2002) p. 33 y Vial (1986) pp. 549 ss.
} 
dispare su ídolo" 51 . A ello habría que agregar la separación de la Iglesia y del Estado, con lo que se puso fin a una tradición institucional que tenía sus orígenes la época indiana.

Se puede concluir que la Constitución Política de 1925 no fue legítima en su origen y que introdujo cambios revolucionarios - no en vano había sido el fruto de una revolución- al régimen constitucional vigente.

\section{IV. ¿LEGITIMIDAD DE EJERCICIO?}

La Constitución de 1925 ¿pudo haberse legitimado en su ejercicio? Ello también parece dudoso. En lo inmediato resulta evidente de que con su promulgación no se superaron las circunstancias revolucionarias y excepcionales que se vivían en Chile. Aunque formalmente seguía gobernando Arturo Alessandri, en la práctica el poder real estaba en manos de los militares jóvenes y de su caudillo, Carlos Ibáñez del Campo. Ello quedaría en evidencia muy luego cuando este último, en su calidad de Ministro de Guerra del primero, terminó forzando su salida, antes de que terminara su período constitucional, cuando ambos se encontraban enfrentados en una sorda disputa por la sucesión presidencial. Cuando Alessandri le solicitó la renuncia a todos sus ministros, el único que se rehusó a dejar el ministerio fue Ibáñez. Más todavía, le comunicó al Presidente que "careciendo de valor, según los preceptos de la antigua y nueva Constitución, todo comunicado sin la firma del ministro respectivo, se sirva no dirigirse a ninguna autoridad u organismo nacional o particular, sin el requisito de mi firma, como único ministro en función" ${ }^{\prime 2}$. Se trataba de un nuevo acto revolucionario o golpe de estado ${ }^{53}$.

La candidatura a la presidencia de Carlos Ibáñez parecía un hecho, cuando finalmente decidió dar una última oportunidad a los partidos para que se pusieran de acuerdo en un candidato común. Así terminó por resultar elegido Presidente de la República -el primero durante la vigencia de la Constitución de 1925- Emiliano Figueroa Larraín ${ }^{54}$. Bajo su mandato, que se extendería solo hasta 1927, cuando se vería obligado a renunciar, la clase política chilena siguió funcionando como si subsistiera el régimen parlamentario. Defenderían este otra vez desde conservadores hasta comunistas, y se seguiría intentando hacer realidad las tradicionales prácticas parlamentarias: interpelaciones, intentos de censura y hasta pre-

51 La Unión (15/5/1925) p. 3. De ahí también el comentario de Hans Kelsen, en el sentido de que la Constitución chilena estaba "muy cerca de las fronteras de aquella forma que hoy se acostumbra denominar una dictadura”. KeLSEN (1926).

52 Monreal (1929) p. 415.

53 Brahm García (2005) pp. 52 ss. La posición de Ibáñez en el gobierno quedaba clara en carta que dirigía a Alessandri, redactada por José Santos Salas (confróntese Correa (1962), tomo II, p. 115) en la que señalaba: "Sobre mi calidad de jefe de la Revolución recayó el cargo de Ministro de Guerra con que me invistieron mis mandantes para que desde él luchara por salvar nuestro programa contra los recios vientos que lo han amenazado y siguen amenazándolo; para que realizara la regeneración que el país espera y que no ha podido lograrse por falta de una cooperación debida. Finalmente subraya este mandato la necesidad de que responda personalmente desde mi puesto de Ministro de la cohesión y disciplina del Ejército y del mantenimiento del orden frente al caos político en que nos encontramos y que tiene amenazada la paz social por obra de esa política "gangrenada" de que habla nuestro manifiesto del 11 de septiembre, y que continúa reinando, a pesar de mi incansable esfuerzo por abolirla”. Diario Ilustrado (1/10/1925) p. 12.

54 BRAHM (2005) pp. 55 ss. 
sionar con la no aprobación de los presupuestos. El mismo Presidente cooperaba, por su parte, al seguir comisionando a un político de su confianza para que le armara el gabinete, el que luego se presentaba ante las cámaras para dar a conocer su programa de gobierno ${ }^{55}$. Parecía que la Constitución de 1925 no hubiera entrado en vigencia.

Al asumir Carlos Ibáñez la primera magistratura en 1927 la situación cambiará radicalmente, aunque tampoco la Constitución pasó a regir en plenitud. Había llegado al poder el caudillo revolucionario para hacer realidad el programa de los militares jóvenes, ante el cual el derecho debía ceder. En el Mensaje Presidencial de 21 de mayo de 1927, pronunciado por Ibáñez en su calidad de Vicepresidente de la República, el día anterior al que fuera elegido Presidente con una amplísima mayoría, ello ya quedaba en evidencia cuando afirmaba: "en nombre de los más elevados intereses de mi patria, yo pido, yo exijo de mis conciudadanos que cooperen franca y lealmente en la obra de reconstrucción nacional en que el Ejecutivo está empeñado y exijo más de los que mayor responsabilidad tienen ante el país (...) Espero esa cooperación (...) Pero si por desgracia, me fuera negada, si intenciones aviesas pretendieran perturbar la obra honrada de un Gobierno cuya finalidad suprema y única es el bien de la patria, no omitiré sacrificios propios ni ajenos para guiar al país por la senda justa, para mantener el orden, aunque al término de mi período, en vez de poder declarar que me he ceñido estrictamente a las leyes, solo pueda afirmar, repitiendo la frase histórica: 'Juro que he salvado a la República"”56. Se anunciaba así que, bajo su gobierno, el autoritarismo presidencial sería llevado al extremo, poniéndose el Presidente incluso por encima de las normas constitucionales. No en vano se ha podido calificar su período presidencial como la "dictadura de Ibáñez"

Tras el derrumbe de su gobierno, duramente golpeado por los efectos de la "gran depresión de 1929 "58, Chile se precipitaría en una profunda crisis que culminaría con la "República Socialista" de 1932, otra vez con los militares como primeros actores y fuera de todo marco constitucional ${ }^{59}$. Recién con la elección de Arturo Alessandri para cumplir con su segundo mandato constitucional a fines de ese año, se puede decir que la Constitución Política de 1925 empezó a regir en forma plena, pese a que los amplísimos poderes de que estaba dotado el Presidente de la República se verían mediatizados muy luego por la acción de los partidos políticos ${ }^{60}$. Sin embargo, ni aun en esas circunstancias los partidos tradicionales estuvieron dispuestos de buen grado a someterse al presidencialismo del texto constitucional. Por el contrario, seguirían defendiendo el parlamentarismo.

El Partido Conservador, por ejemplo, que en su convención de 1929 había terminado por aceptar el presidencialismo, apenas caído Ibáñez, en la de 1932, volvía a aprobar como parte de su programa "el establecimiento de un régimen parlamentario de gobierno reformado con la adopción de quórums, procedimientos y plazos para las proposiciones

55 Donoso (1976) y Brahm et al. (2002) pp. 40 ss.

56 Diario Ilustrado $(21 / 5 / 1927)$.

57 VIAL (1996).

58 BRAHM (2012).

59 VIAL (2001).

60 Bravo Lira (1986) pp. 38 ss. 
de censura ministerial, que deberán ser motivadas; y con la facultad concedida al Presidente de la República de disolver la Cámara de Diputados, sujeto a plazos y condiciones preestablecidas"61. Por su parte los radicales, a un mes de la caída de Ibáñez, ya presentaban un proyecto de reforma constitucional en el que se introducía la censura a los ministros como atribución de la Cámara de Diputados, al más puro estilo parlamentario ${ }^{62}$.

Esa sería la constante de los partidos tradicionales en los años que siguieron a la entrada en vigencia de la nueva Constitución. Todavía en la XIV Convención Nacional del Partido Conservador, celebrada en junio de 1947, se postulaba como aspiración el establecimiento de un "sistema parlamentario disciplinado, sobre la base de mayorías estables, en el que los ministros no deben renunciar sino ante el voto de la mayoría de los diputados en ejercicio y en el cual el Presidente de la República pueda disolver la Cámara Política"63.

Más notable todavía es el caso del Partido Radical, el que seguiría defendiendo el régimen parlamentario, pese a que de sus filas saldrían los Presidentes que gobernaron Chile entre 1938 y 1952. Por ejemplo, en la XII Convención Nacional de 1939 se señalaba que el partido aspiraba "a la implantación del régimen parlamentario de Gobierno, según el sistema clásico inglés" ${ }^{4}$.

Con algunos matices seguía la misma línea el tercero de los partidos tradicionales, el Liberal. En su VIII Convención Nacional celebrada en 1947 concluía que "el régimen parlamentario, debidamente reglamentado y establecido sobre la base de partidos fuertes y bien organizados, es el que asegura mejor las libertades y el buen gobierno de una nación; pero acepta como una necesidad derivada de nuestro actual estado político y social el régimen presidencial, sin perjuicio de introducirle las modificaciones indispensables para asegurar, por parte del Ejecutivo, el cumplimiento estricto de las leyes y los acuerdos que adopte la Cámara de Diputados en ejercicio de las facultades fiscalizadoras" ${ }^{65}$.

Pese a todo lo anterior -aunque se presentaron proyectos que iban en esa líneanunca se aprobaron reformas que introdujeran instituciones parlamentarias. Ello se explica quizá por el hecho de que, los mismos políticos que desde la tribuna parlamentaria se quejaban de la omnipotencia del ejecutivo, una vez que llegaban al gobierno, cambiaban de opinión. Ahora les parecía que la Constitución no era suficientemente presidencialista y exigían se la reformara para dotar de mayores poderes al Presidente. Como ha señalado Fernando Silva Vargas, "la paradoja del sistema político instaurado por la carta de 1925 es que un presidente poderoso -y cada vez lo sería más, al compás del aumento de la injerencia estatal- necesitaba del concurso de partidos políticos, concurso que se pagaba con cuotas de dicho poder. El Presidente de la carta de 1925 fue, esencialmente, un árbitro entre los integrantes de una coalición”66. Frente a la presión partidaria, cuasi oligárquica, que provenía muchas veces de la directiva del mismo partido del Presidente de la Repú-

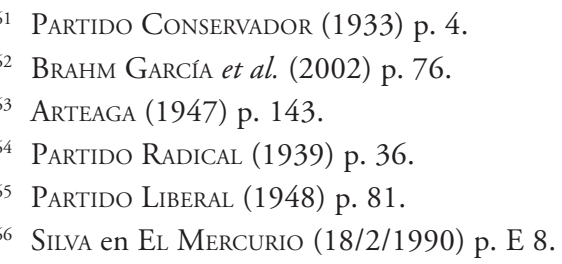


blica, este, al observar que "a pesar de sus buenas intenciones, no obtiene los resultados esperados de su gestión, busca las explicaciones. La que surge de inmediato, intuitivamente, es la preponderancia del Congreso sobre él. Y la solución es sencilla: reducir la injerencia del parlamento" 67.

Todo ello es lo que explica el que, más allá de la postura de las dirigencias partidarias, críticas del régimen establecido en la Constitución de 1925, la primera reforma de la misma - promulgada en 1943- viniera a reforzar el presidencialismo ${ }^{68}$. De ahí en adelante pasó a ser una constante el que los Presidentes de la República, cualquiera que fuera su filiación política, se transformaran en duros críticos de la Constitución vigente, y buscaran por todos los medios reformarla en un sentido todavía más presidencialista.

En el caso de Carlos Ibáńez, ya en julio de 1954 alertaba del "resurgimiento del parlamentarismo, que actualmente se asemeja mucho a aquel otro que introdujera en el país el desgobierno y la anarquía" 99 . A continuación crearía una "Comisión Consultiva" que debía preparar un proyecto de reforma constitucional, la que inició sus funciones el 31 de julio de 1954, con un discurso programático de Ibáñez en el que propiciaba "el completo restablecimiento del régimen presidencial de Gobierno, y para lograr ese propósito en su integridad, es necesario derogar todas las disposiciones constitucionales y legales que en forma directa o indirecta permiten la intervención del Congreso en funciones que, de acuerdo con la doctrina, con el espíritu y con el propio texto de preceptos fundamentales de la Constitución Política del estado, corresponden al Poder Ejecutivo"70. El trabajo de esa Comisión no llegaría a ser presentado al parlamento para su discusión ${ }^{71}$.

Particularmente crítico con el funcionamiento del régimen de gobierno contemplado en la Constitución de 1925, lo sería el Presidente Jorge Alessandri Rodríguez, desde el momento en que, en su opinión, este impedía al Jefe del Estado desplegar todo su poder, pues en la práctica estaría subordinado al Parlamento. De ahí que exigiera se introdujeran profundas reformas en el texto constitucional para reforzar los poderes del titular del Ejecutivo, aunque ellas debían entrar en vigencia cuando el mismo terminara su mandato. Todavía en su último Mensaje, de mayo de 1964, señalaba: "Esa y no otra es la Reforma Estructural verdadera que Chile necesita. Esa es la verdadera revolución -como ahora se dice- que debe hacerse; la que restrinja drásticamente las iniciativas de los parlamentarios y que los responsabilice en los actos que ejecutan como tales, como ocurre con el Presidente de la República, con los Ministros de Estado, con los miembros de los altos Tribunales de Justicia y de la Administración Pública. La que permita someter a la decisión popular los conflictos entre el Ejecutivo y el Parlamento; la que evite la dictación de leyes que violen la Constitución y autorice en ciertos casos a delegar facultades legislativas en el Presidente de la República tratándose de materias técnicas o que exijan soluciones rápidas; la que contemple normas que impongan sanciones a la intervención de los parlamentarios en la Administración Pú-

\footnotetext{
67 Silva en El Mercurio (18/2/1990) p. E 9.

68 VALENCIA (1986) pp. 240 ss.

69 La NaCión (11/7/1954) p. 9.

70 La NaCión (23/7/1954) p. 1.

71 Confróntese con Brahm et al. (2002) pp. 125 ss.
} 
blica, etc. Lo cual es anacrónico, es la causa última del desconcierto en que se desenvuelve nuestra vida pública que ha llegado a límites extremos, por lo cual no puede continuar sin abocarnos a la catástrofe definitiva"72.

Aunque Alessandri presentaría al Congreso un completo proyecto de reforma constitucional, que buscaba hacer realidad sus propuestas este no llegaría a ser aprobado ${ }^{73}$. Sin contar con una mayoría parlamentaria -al igual que le había ocurrido a su antecesor- y en un ambiente ya muy radicalizado, resultaba imposible que pudiera hacer realidad su concepción de lo que debía ser el mejor régimen de gobierno para Chile.

La crítica a la Constitución de 1925 y la necesidad que habría de robustecer los poderes del Presidente de la República, alcanzó cotas extremas con el triunfo de Eduardo Frei Montalva, el candidato de la Democracia Cristiana, en las presidenciales de 1964. Llegaban al poder los partidos "ideológicos"74, poseedores de una Weltanschauung omnicomprensiva que apuntaban a la creación de una nueva sociedad, para lo que era necesario introducir reformas radicales en todos los ámbitos de la vida nacional, lo que exigía la existencia de un Poder Ejecutivo que dispusiera del máximo de poderes y dotado de adecuadas herramientas de planificación.

En su discurso de proclamación por el Frente de Profesionales y Técnicos que apoyaban su candidatura, de junio de 1964, afirmaba Frei: "Asistimos a una vasta revolución. Han muerto viejas fórmulas y nace una nueva edad. Sería inútil negarlo. Por eso el mundo entero camina a través de un proceso de cambios que a todos los pueblos alcanza, y que hace inoperantes viejas fórmulas y antiguas instituciones. Ya nadie discute que en el mundo, como en nuestra América y en Chile, hay un proceso revolucionario"75. En el plano constitucional -agregaba en la misma ocasión- "el Presidente de la República debe tener el derecho de consultar directamente al pueblo por medio del plebiscito o referéndum acerca de los asuntos de gran trascendencia nacional. El Ejecutivo debe contar con un organismo técnico central de planificación; debe plantear un programa de acción con claridad y realizarlo con decisión; debe tener facultades suficientes y la iniciativa para mantener la unidad en la operación económica del Estado"76.

Estas ideas se verían reforzadas por los grandes triunfos obtenidos por la Democracia Cristiana no solo en las presidenciales de 1964, sino también en las parlamentarias del año siguiente. Pese a ello, no alcanzaría una mayoría en las cámaras que le permitiera hacer realidad su programa, lo que le impulsaría a presentar una serie de proyectos de reforma constitucional. "El pueblo elige su Gobierno -señalaba Frei en un discurso pronunciado para defender su proyecto de reforma presentado el año 1967- y elige un Parlamento para cumplir el programa que el Gobierno comprometió, y luego ocurre que aquellos que fueron derrotados, que son minoría, basados en el hecho de la renovación parcial del Senado, conservando muchos de ellos cargos que saben a conciencia que perderían si hubiera

\footnotetext{
72 Alessandri (1964).

73 BRAHM et al. (2002) pp. 152 ss.

${ }^{74}$ Bravo (1986) pp. 70 ss. En palabras de GóngOra (1981) pp. 126 ss., se iniciaba la época de las "planificaciones globales".

75 FreI, p. 47.

76 FreI, p. 60.
} 
elecciones, tratan de hacer imposible la tarea del Gobierno"77. En el fondo se pretendía introducir como parte de las atribuciones presidenciales la planificación económica; de ahí que se miraran, en ese aspecto, con alguna envidia y hoy día incomprensible ilusión, los modelos del bloque comunista ${ }^{78}$. Pero a esas alturas el enfrentamiento ideológico era tan fuerte en las cámaras, que resultaría imposible que los proyectos de Frei se pudieran hacer realidad. Recién en 1970 se aprobaría una reforma constitucional en la que se acogieron parte de sus ideas ${ }^{79}$.

Salvador Allende también llegó al poder con el propósito de cambiar de raíz el sistema constitucional chileno. No en vano asumía la primera magistratura apoyado por una coalición de partidos donde destacaban los de filiación marxista, como el suyo que era el Socialista, esto en medio de ese gran enfrentamiento ideológico que era la Guerra Fría. Aunque en el seno de la Unidad Popular había unidad en los fines -la transformación de nuestro país en una "democracia popular" de acuerdo a los modelos imperantes en el bloque soviético- se postulaban para alcanzarlos métodos diferentes. Mientras algunos sectores extremos habían llegado a propiciar hasta la vía violenta ${ }^{80}$, Salvador Allende defendería su vía "pluralista", aquella que se aprovechaba de la "legalidad burguesa" para impulsar los cambios. Como lo señalaba en su intervención en el pleno nacional del Partido Socialista celebrado en Algarrobo en marzo de 1972, lo que correspondía era "transformar el aparato burocrático, el aparato del Estado como totalidad, la propia Carta Fundamental, en su sentido de clase", pero había que aceptar la posibilidad "de que esa institucionalidad pueda dar paso a través de sus propios cauces a una institucionalidad con distinto sentido de clase”. El gran impulsor del proceso revolucionario había que buscarlo "en la estructura económica, en las relaciones de producción nuevas que estamos poniendo en funcionamiento de modo acelerado, en la conciencia de los trabajadores, en las nuevas organizaciones de los trabajadores que los cambios en la infraestructura deben producir, y que los partidos populares deben estimular y guiar". Su conclusión era que "la negación del actual régimen institucional chileno" no podía "concebirse como producto de la acción voluntarista de una minoría osada, sino como fruto de la acción consciente y organizada de las grandes masas". Al final de cuentas, "la tarea del momento es conquistar el parlamento. Ese es el camino más corto hacia el cambio cualitativo del aparato del Estado" $"$.

Por lo demás, la desafección hacia la institucionalidad vigente se manifestaba ya en el programa mismo de la Unidad Popular, en el acápite titulado "Un nuevo orden institucional: el Estado popular". En él se señalaba que "a través de un proceso de democratización en todos los niveles y de una movilización organizada de las masas se construirá desde la

\footnotetext{
77 La NaCión (20/1/1967) p. 4.

78 La Nación (5/2/1967) p. 10. Según señalaba Francisco Cumplido, "los países marxistas, las monocracias marxistas tienen un poder de programación y ejecución extraordinariamente eficaz. ¿¿Por qué? Porque existe un partido único que orienta ideológicamente al Gobierno; luego, las decisiones fundamentales no están sujetas a una revisión continua por la opinión pública, sino que son el partido y el Gobierno los que las impulsan”. La Nación (5/2/19679 p. 10.

79 Valencia (1986) pp. 247 ss.

80 Jobet (1971), tomo II, pp. 107 ss.

81 Allende (1989) pp. 157 ss.
} 
base la nueva estructura del poder (...) Una nueva Constitución Política institucionalizará la incorporación masiva del pueblo al poder estatal (...) Se creará una organización única del Estado estructurada a nivel nacional, regional y local que tendrá a la Asamblea del Pueblo como órgano superior de poder (...) La Asamblea del Pueblo será la Cámara única que expresará nacionalmente la soberanía popular. En ella confluirán y se manifestarán las diversas corrientes de opinión (...) Este sistema permitirá suprimir de raíz los vicios de que han adolecido en Chile tanto el presidencialismo dictatorial, como el parlamentarismo corrompido" 82 . Allende presentaría al Congreso un proyecto de reforma constitucional para hacer realidad estas propuestas, pero no contaba con suficiente apoyo en las cámaras para impulsarlo ${ }^{83}$.

Se debe agregar también que Salvador Allende, al igual que sus antecesores, consideraba que con el régimen vigente le resultaba muy difícil gobernar; que resurgía una suerte de "parlamentarismo", como afirmaría en su tercer mensaje presidencial ${ }^{84}$.

De todo lo anterior se puede concluir que la referencia a la Constitución de 1925 que hacían ambos bandos enfrentados en la crisis final de 1973 era más bien formal que de fondo. Recurrían a ese texto, porque era el que estaba vigente: Allende para destacar que siempre lo había respetado; sus opositores para señalar que lo había violado de forma manifiesta ${ }^{85}$; pero ninguno estaba conforme con el mismo y habían pretendido reformarlo de manera radical durante los últimos años de su vigencia.

\section{CONCLUSIÓN}

Desde una perspectiva histórico-jurídica no parece sensato, como algunos han planteado, volver a la Constitución de 1925 para así destrabar la discusión relativa a la mejor manera de reformar la Constitución vigente. Para defender esa postura se aduce la existencia de una supuesta tradición constitucional que se habría iniciado con la Constitución de 1828 y se habría continuado en las de 1833 y 1925 para romperse con la de 1980, pero esa línea está lejos de ser clara. Pese a presentarse formalmente como una reforma, la Constitución de 1833, obra fundamentalmente de Mariano Egaña, se aprobó después de una guerra civil que puso fin al período liberal, no respetó las normas sobre su reforma contenidas en la Constitución vigente e introdujo profundos cambios en su contenido, inspirados muchos de ellos en modelos extranjeros.

Más traumático todavía fue el proceso de generación de la Constitución Política de 1925. En un ambiente marcado por la intervención militar de septiembre de 1924 que culminó con la licencia dada al Presidente Arturo Alessandri, su vuelta a Chile para culminar su período presidencial, aunque ahora bajo tutela militar -Carlos Ibáñez se mantendría como Ministro de Guerra-, su elaboración se daría sin considerar para nada las normas constitucionales vigentes y como una imposición de los militares y Alessandri sobre las diri-

\footnotetext{
82 Cita según Lavín (1989) pp. 165 ss.

83 BRAHM et al. (2002) pp. 222 ss.

84 Allende (1989) p. 191.

85 Fontaine (2018) p. 44.
} 
gencias partidarias, aunque recibiría una cierta sanción popular en un plebiscito desarrollado en circunstancias de excepcionalidad constitucional.

Tampoco se puede afirmar el que pese a sus orígenes espurios, la Constitución se haya podido legitimar en su ejercicio. En efecto, en lo inmediato, bajo el gobierno de Emiliano Figueroa, los partidos siguieron actuando como si siguiera vigente el régimen parlamentario. Bajo el gobierno de Ibáñez, en cambio, se practicó un autoritarismo que iba mucho más allá del presidencialismo de la carta constitucional. Una vez alcanzada la estabilidad institucional a partir del segundo gobierno de Arturo Alessandri, los partidos tradicionales siguieron defendiendo, por lo menos hasta fines de los años cuarenta, la vuelta al parlamentarismo. Luego, desde la llegada de Carlos Ibáñez del Campo al poder en 1952, todos los presidentes de la República estuvieron de acuerdo en criticar el texto vigente por considerar que no les concedía las suficientes atribuciones para gobernar ya que daba un poder excesivo al Congreso Nacional.

Pese a que se terminaron por introducir algunas reformas constitucionales que reforzaban algo el poder del Ejecutivo, ni Alessandri, ni Frei, ni Allende lograrían hacer aprobar los cambios que deseaban. Sus pretensiones se estrellarían con la falta de mayorías en un contexto de radicalización política extrema, marcado por el bloqueo que se derivaba de la división de las cámaras en tres tercios irreconciliables. En el fondo, por lo menos desde la década de los sesenta, ningún sector estaba de acuerdo con el régimen establecido por la Constitución vigente y lo hubieran sometido a profundas reformas si hubieran tenido posibilidades para ello.

\section{BIBLIOGRAFÍA CITADA}

Actas oficiales de las sesiones celebradas por la Comisión y Subcomisiones encargadas del estudio del proyecto de nueva Constitución política de la República (1926) (Santiago, Imprenta Universitaria).

Alessandri, Jorge (1964): "Mensaje de S.E. el Presidente de la República al Congreso Nacional", Sesiones de la Cámara de Diputados, Legislatura Ordinaria, tomo II, pp. 1158-1188.

Allende Gossens, Salvador (1989): Obras escogidas (1970-1973) (ed. Patricio Quiroga, Barcelona, Crítica).

Alvarado R., Claudio (2016): La ilusión constitucional. Sentido y límites del proceso constituyente (Santiago, Instituto de Estudios de la Sociedad).

Arteaga Undurraga, Ignacio (comp.) (1947): Partido Conservador. XIV Convención Nacional 1947. Notas para la historia política del partido Conservador (Santiago, Imprenta Chile).

Atria, Fernando (2013): La Constitución tramposa (Santiago, LOM Ediciones).

Barros Arana, Diego (1884-1902): Historia general de Chile (Santiago, Editorial Nascimento).

Brahm García, Enrique (1992): Tendencias criticas en el conservantismo después de Portales (Santiago, Instituto de Estudios Generales).

Brahm García, Enrique (2005): "La elección presidencial de 1925: el candidato equivocado", en San Francisco, Alejandro y Soto, Ángel (edits.) (Santiago, Centro de Estudios Bicentenario). 
Brahm García, Enrique (2007): Mariano Egaña. Derecho y política en la fundación de la república conservadora (Santiago, Centro de Estudios Bicentenario).

Brahm García, Enrique (2012): "Algunos aspectos del proceso de socialización del derecho de propiedad en Chile durante el gobierno del general Carlos Ibáñez del Campo (19271931), Rechtsgeschichte. Legal History, No 20: pp. 234-256.

Brahm García, Enrique (2013): Hitler y la Segunda Guerra Mundial (Santiago, Editorial Universitaria).

Brahm García, Enrique (2017): "El Partido Conservador frente a la crisis constitucional de 1925", Revista Chilena de Derecho, vol. 44, N 1: pp. 261-285.

Brahm García, Enrique, Bertelsen Repetto, Raúl y Amunátegui Echeverría, Andrés (2002): Régimen de gobierno en Chile. ¿Presidencialismo o parlamentarismo? 1925-1973 (Santiago, Editorial Jurídica de Chile).

Bravo Lira, Bernardino (1986): Régimen de gobierno y partidos politicos en Chile 1924-1973 (Santiago, Editorial Jurídica de Chile).

Carrasco Delgado, Sergio (1983): Génesis y vigencia de los textos constitucionales chilenos (Santiago, Editorial Jurídica de Chile).

Collier, Simon (2005): Chile. La construcción de una república 1830-1865 (Santiago, Ediciones de la Universidad Católica de Chile).

Collier, Simon y Sater, William, F. (1998): Historia de Chile 1808-1994 (España, Cambridge University Press).

Correa Prieto, Luis (1962): El Presidente Ibáñez. La politica y los políticos. Apuntes para la Historia (Santiago, Editorial Orbe).

Correa Sutil, Sofía (2015): "Los procesos constituyentes en la historia de Chile: lecciones para el presente", Estudios Públicos, vol. 137: pp. 43-85.

Donoso, Crescente (1976): "Notas sobre el origen, acatamiento y desgaste del régimen presidencial, 1925-1973", Historia, № 13: pp. 271-352.

Escobar Guic, Dina e Ivulic Gómez, Jorge (1984): "El manifiesto del 11 de septiembre de 1924”, Dimensión Histórica de Chile, N 1: pp. 130-139.

Eyzaguirre, Jaime (1977): Historia de Chile (Santiago, Editorial Zig-Zag).

Fontaine, Arturo, Ossa, Juan luis, Mascareño, Aldo, Cristi, Renato, Herrera, Hugo, TrujILLO, Joaquín (2018): 1925. Continuidad republicana y legitimidad constitucional: una propuesta (Santiago, Catalonia).

Frei Montalva, Eduardo (sin fecha): Dos discursos. Chile 1964-1970 (lugar de edición, s.e.). Galdames, Luis (1925): La evolución constitucional de Chile (Santiago, Editorial Balcells).

Ginsburg, Tom (2014): “¿Fruto de la parra envenenada? Algunas observaciones comparadas sobre la constitución chilena”, Estudios Públicos, vol. 133: pp. 1-36.

Góngora, Mario (1981): Ensayo histórico sobre la noción de Estado en Chile en los siglos XIX y XX (Santiago, Editorial La Ciudad).

Hildebrandt, Horst (Hrsg.) (1979): Die deutschen Verfassungen des 19. und 20. Jahrhunderts (Paderborn, Ferdinand Schöningh).

Jaksic, Iván y Serrano, Sol (2010): "El gobierno y las libertades. La ruta del liberalismo chileno en el siglo XIX”, Estudios Públicos, vol. 118: pp. 69-105. 
Jobet, Julio César (1971): El Partido Socialista de Chile (Santiago, Ediciones Prensa Latinoamérica).

Kelsen, Hans (1926): “Observaciones sobre la Constitución Chilena”, Zeitschrift für öffentliches Recht, № 5: pp. 616-619.

Lavín, Julio (1989): El Congreso nacional en la crisis de la Constitución de 1925, Tesis para optar al grado de Magíster en Ciencia Política de la Universidad de Chile.

Partido Conservador (1933): Programa y Estatutos aprobados en la Convención General del partido (Santiago, s.e.).

Partido Liberal (1948): VIII Convención (Santiago, s.e.).

Partido Radical (1939): Programa, Estatutos, Reglamentos: 1939 (Santiago, s.e.).

Pinto Vallejos, Julio y Valdivia Ortiz de Zárate, Verónica (2009): ¿Chilenos todos? La construcción social de la nación (1810-1840) (Santiago, LOM Ediciones).

Salazar, Gabriel (2005): Construcción de Estado en Chile (1800-1837) (Santiago, Sudamericana).

Salazar, Gabriel y PINTo, Julio (1999): Historia contemporánea de Chile I. Estado, legitimidad, ciudadanía (Santiago, LOM Ediciones).

Sesiones de los Cuerpos Legislativos de la República de Chile (editados por Valentín Letelier) (1887): (Santiago, Imprenta Cervantes).

Silva Vargas, Fernando (1990): “Diagnósticos equivocados", El Mercurio (18/2/1990) p. E 8.

Tagle D., Matías (editor) (1992): La crisis de la democracia en Chile. Antecedentes y causas (Santiago, Editorial Andrés Bello).

Valencia Avaria, Luis (1986): Anales de la República (Santiago, Editorial Andrés Bello).

VIAL, Gonzalo (1986): Historia de Chile (1891-1973), Arturo Alessandri y los golpes militares (1920-1925), vol. III, (Santiago, Santillana).

Vial, Gonzalo (1996): Historia de Chile (1891-1973), La dictadura de Ibáñez (1925-1931), vol. IV (Santiago, Editorial Fundación).

Vial, Gonzalo (2001): Historia de Chile (1891-1973), De la República Socialista al Frente Popular (1931-1938), vol. V (Santiago, Editorial Zig-Zag).

Welsch Crespo, Margaret (1977): "La influencia del voto particular de Egaña en la redacción de la Constitución de 1833” (Tesis, Escuela de Derecho, U. Católica de Valparaíso). 